Forthcoming in Applied Research in Quality of Life doi:10.1007/s11482-016-9480-9

http://link.springer.com/article/10.1007/s11482-016-9480-9

\title{
Neighborhoods, Family Functioning, and Mothers' Mental Health for Families with a Child with an Autism Spectrum Disorder
}

Mothers of children with autism spectrum disorders (ASD) typically report lower overall family functioning and worse mental health. Neighborhood conditions are found to positively influence family functioning and mental health in the general population. Employing a process-personcontext model, this study extends these literatures to examine whether various neighborhood conditions - both positive and negative - affect mothers' mental health and the overall functioning of families with a child with an ASD. Simultaneous equation path analysis of a nationally representative sample of children in the US finds neighborhood support to be positively and significantly associated with mothers' mental health and the overall functioning of families with a child with an ASD. However, neighborhood amenities and neighborhood deficiencies were not significantly associated with either mothers' mental health or family functioning. Neighborhood support can play a vital role in improved subjective quality of life for mothers with a child on the autism spectrum.

Keywords: Autism; Neighborhoods; Quality of Life; Mental Health; Mothers; Children; Family Functioning; United States 


\section{Introduction}

Autism spectrum disorders (ASD) are rapidly becoming a more visible aspect of childhood in the United States where now one in 68 children receives a diagnosis (Centers for Disease Control 2014). This continues the trend of increased prevalence among children in the United States and Europe (Benjak, Vuletić, and Kolarić 2011; Parner, Schnedel, and Thorsen 2008; Schieve et al. 2012). ASD are a range of developmental disabilities usually characterized by deficiencies in social communication and interaction as well as restricted and repetitive patterns of interests, behaviors, and activities. ASD are uniquely challenging in that they are most often lifelong disabilities, manifest themselves in extremely disruptive ways, and because there are usually no obvious physical markers of disability, result in increased probability of strained social encounters (Farrugia 2009). For example, when a child does not meet the expectations held by others of age appropriate behavior, informal sanctions are commonly directed toward the child or the parent(s).

Raising a child with an ASD presents a number of challenges to parents and families.

Overall family functioning and the mental health of mothers are particularly affected (Hayes and Watson 2013; Khanna et al. 2011) because they tend to bear greater responsibility for caring for the disabled child (Gray 1997, 2002, 2003; Hastings et al. 2005). In light of these difficulties, a large body of research examines what is associated with positive outcomes for those families in spite of their child's disabilities. A number of factors internal to parents such as human capital, various coping strategies, optimism, or employing particular narratives are found to improve various outcomes (Bayat 2007; Coulthard and Fitzgerald 1999; Ekas, Lickenbrock, and Whitman 2010). Factors external to families, such as social support from family and friends, support groups, religious organizations, and educators are also associated with improved outcomes for 
families with children with an ASD (Boyd 2002; Bromley et al. 2004; Coulthard and Fitzgerald 1999; Gray 2006; Lai and Oei 2014; Sikora et al. 2013; Zablotsky, Bradshaw, and Stuart 2013). While some studies label support from neighbors as possible sources of informal support (Boyd 2002), no prior work explicitly tests the direct and indirect effects of neighborhood characteristics on family functioning and mothers' mental health. This gap in the literature is significant given the large body of research on the general public demonstrating the importance of neighborhoods on physical health, mental health, and overall family functioning (Ellen, Mijanovich, and Dillman 2001; Fan and Chen 2012; Truong and Ma 2006). Furthermore, the ecological model of human development (Bronfenbrenner 1977, 1986) highlights the importance of the environment for human flourishing. The process-person-context model suggests that the proximal processes surrounding people - their interpersonal and environmental interactions play a significant role in their quality of life (Bronfenbrenner 1994, 1999). However, the question remains: Do neighborhood conditions significantly influence family functioning and mothers' mental health for families with a child with an ASD? Autism, Family Functioning, and Mothers' Mental Health

The challenges associated with raising a child with an ASD dramatically influence families. These families experience more stress and lower overall family functioning (Benjak et al. 2011; Hayes and Watson 2013; Khanna et al. 2011). Parents of children with ASD report more stress, depression, stigmatization, anger, anxiety, and overall lower well-being (Benjak et al. 2011; Bromley et al. 2004; Ekas et al. 2010; Ekas, Whitman, and Shivers 2009; Hastings 2008; Sawyer et al. 2010; Zablotsky et al. 2013). These families are also more likely to report unmet health care needs, social isolation, negative employment outcomes, greater time burdens in providing health care, financial problems, and unmet child-care needs (Chiri and Warfield 
2012; Kogan et al. 2008; Miller, Nugent, and Russell 2015). In fact, many of these negative outcomes are more ubiquitous for those families with a child with an ASD compared to families raising a typically-developing child, a child with Downs Syndrome, or children with other types of intellectual disabilities (Chiri and Warfield 2012; Dabrowska and Pisula 2010; Sikora et al. 2013).

While the strains of raising a child with an ASD are felt throughout families, mothers bear most of the burden. This is attributed to the fact that mothers of children with ASD typically take on a majority of the caregiver demands (Gray 1997). This is primarily due to the cultural expectation that childcare is primarily women's work and that men's employment leaves them less time to perform childcare (Sayer 2005). Many mothers of children with ASD also lack any sort of alternative role, like employment, which would provide them a small break from their parenting duties whereas fathers tend to have built in "respite" time when they leave for work each day (Gray 2002, 2003). Due to mothers' greater responsibility for their ASD child's care (Gray 1997, 2002, 2003; Hastings et al. 2005), there are simply more opportunities for them to face challenging situations due to the child's disabilities and reactions from the public. Mothers with a child with an ASD are more likely to experience both courtesy stigma and blame when the "performance of domesticity" - the presentation of the family as "normal" to the outside world fails (Francis 2012; Gray 1997, 2002). This leads to these mothers faring worse on a variety of outcomes: stress (Dabrowska and Pisula 2010), psychological distress (Gray 2003; Hastings 2008; Jones et al. 2013), depression (Hastings et al. 2005), anxiety (Hastings 2003), and mental health problems (Sawyer et al. 2010). Neighborhoods, Family Functioning, and Mental Health 
Prior work points to various factors that help mitigate many of the negative outcomes of raising a child with an ASD. Social support systems are consistently found to help parents; those who receive more social support tend to fare better than those receiving less social support (Bishop et al. 2007; Boyd 2002; Bromley et al. 2004; Gray 2006; Lai and Oei 2014; Sikora et al. 2013; Zablotsky et al. 2013). Zablotsky and colleagues (2013) included measures of perceived neighborhood support on mothers' mental health and parental stress, but were unable to examine neighborhood amenities and deficiencies, or the direct and indirect effects of neighborhood contexts on mothers' mental health and family functioning. Therefore, no previous research specifically addresses how perceived support, physical amenities, and physical deficiencies of the neighborhood are associated - both directly and indirectly - with overall family functioning and the mental health of mothers of children with an ASD. Given that human movement is generally limited (Gonzalez, Hidalgo, and Barabasi 2008) and families with children with an ASD tend to restrict their interactions due to the probability of negative exchanges (Gray 2002), this is an oversight. Regarding families of children with an ASD specifically, spatial patterns of interaction are significant for it is in the surrounding community that parents of children with an ASD will interact with other parents of children, and at times, parents of children with an ASD (Liu, King, and Bearman 2010).

In the general population, neighborhoods significantly influence overall family functioning (Fan and Chen 2012; Mannon and Brooks 2006). Regarding families of children with disabilities, living in a supportive community is associated with better overall family functioning and coping (Park, Turnbull, Turnbull 2002). Neighborhoods can also adversely affect family functioning, encouraging negative outcomes like marital instability (South 2001), divorce (South and Lloyd 1995; Trent and South 2003), and premarital childbearing (South and 
Crowder 1999). Prior research highlights the importance of the neighborhood and community on both physical and mental health (Ellen et al. 2001; Truong and Ma 2006). Regarding mental health in particular, there is a strong association between the physical environment (e.g. green spaces, parks, neighborhood noise) and mental health (Guite et al. 2006; Truong and Ma 2006). Researchers find that the perception of one's surrounding community is just as important as the actual objective condition the neighborhood is in, or the amount of social support the neighborhood offers (Gale et al. 2011; Jones et al. 2014). Families and individuals who perceive support from their neighborhood tend to fare better than those who do not identify their neighborhood as supportive.

Neighborhoods influence family functioning and the mental health of residents in different ways. First, they offer opportunities for social interaction which are shown to be important for mothers of children with autism (Bishop et al. 2007; Boyd 2002; Lai and Oei 2014; Sikora et al. 2013). "Escape facilities" within the neighborhood - green spaces, parks, playgrounds - significantly influence well-being within neighborhoods by providing not only places for the opportunities for social interaction to occur but also respite from the stresses found inside homes (Chu, Thorne, and Guite 2004; Guite et al. 2006). Second, the social networks that operate within neighborhoods work to transmit information, norms, and social support. Neighborhood characteristics significantly influence these network patterns (Cattell 2001). For parents of children with an ASD, these networks can conduct particularly important information concerning good doctors in the area, therapists, social workers, schools, entertainment, and other activities (Liu et al. 2010). Social participation, made possible through the opportunities the neighborhood provides for social interaction as well as the social networks present within the neighborhood, is also linked to improved mental health. Social participation engenders social 
integration, feelings of safety, cooperation, trust, reciprocity, and a sense of belonging (Chu et al. 2004). Third, deficiencies in the physical environment, which lead to greater likelihood of injuries and negative perceptions of the community, many times produce greater distress for those residing there (Ellen et al. 2001). Finally, exposure to violence, crime, noise, or other negative events, or the perception of exposure to these things from objects like offensive graffiti and trash, can also increase stress (Guite et al. 2006).

\section{Process-Person-Context Model for Mental Health of Mothers' of Children with Autism}

The present examination of mothers' mental health, family functioning, and neighborhood characteristics draws upon the ecological model of human development literature (Bronfenbrenner 1977, 1986, 1994, 1999). The ecology of human development focuses upon the relationship of humans and the environments that surround them. The ecological environment consists of a nested arrangement of systems: microsystems, mesosystems, exosystems, macrosystems, and in later formulations, chronosystems (Bronfenbrenner 1977, 1994). The ecological model highlights the importance of how intrafamilial processes and individual outcomes are affected by extrafamilial conditions (Bronfenbrenner 1986).

Of particular importance in the ecological model literature is the later focus on proximal processes and the process-person-context model (Bronfenbrenner 1994, 1999). Proximal processes focus on the interaction of humans with their immediate environment which include both interpersonal interaction (family functioning) and interaction with objects and symbols (the built environment). Proximal processes can vary in form, power, and content depending on the characteristics of the individual and the environment surrounding them (Bronfenbrenner 1999). The key point, however, is that proximal processes can serve to buffer environmental influences (Bronfenbrenner 1994). In this particular study, the process-person-context model is most useful. 
For our purposes "process" refers to family interaction and functioning. "Person" denotes the various individual descriptors of the mother and child with autism. "Context" signifies the environmental context that includes neighborhood support, neighborhood amenities, and neighborhood detractions. Through utilizing the process-person-context model this analysis is able to place the mother, child with autism, and their family in the proper perspective and account for the fact that individuals and families are affected by intrafamilial processes and extrafamilial conditions.

Using a nationally representative survey of children's health in the United States and simultaneous equation path analysis to model the process-person-context model, this analysis examines the mental health of mothers' with children with autism. The results from this study will help to determine if (1) neighborhood conditions significantly influence the mental health of mothers' of children with an ASD and overall family functioning, and (2) confirm whether overall family functioning mediates the relationship between neighborhood conditions and mothers' mental health.

\section{Data}

In order to test these relationships this analysis utilizes the 2007 and 2011/2012 National Survey of Children's Health (NSCH), conducted by the Centers for Disease Control and Prevention's National Center for Health Statistics and directed by the Health Resources and Services Administration. Both waves of the NSCH are publically available and nationally representative data of households in the United States with children less than 18 years of age in each of the 50 states and the District of Columbia. Both waves are utilized in this analysis given the relative rarity of ASD in large samples of the population. Supplementary analyses (available upon request) suggest that the results are not sensitive to the year the data was collected. 
In each wave the NSCH used a random-digit dialing method to identify each household with one child randomly selected to be the subject of the interview. Interviews were completed in English, Spanish, Mandarin, Cantonese, Vietnamese, and Korean. The parent or guardian who lived with the selected child and knew the most about their overall health answered all questions. In addition to the health of the randomly selected child, the NSCH also asked questions pertaining to family behaviors, parents' health status, family activities, and perceptions of the neighborhood. For the $2007 \mathrm{NSCH}$, the overall weighted response rate at the national level was 46.7\% with 91,652 households completing the interviews. For the 2011/2012 NSCH, the overall weighted response rate at the national level was $23.0 \%$ with 95,677 surveys completed. ${ }^{1}$ Please see Blumberg et al. (2012) and Blumberg et al. (2013) for additional information concerning survey design and execution for the 2007 and 2011/2012 waves, respectively.

The sample for this study focuses on those families with children with an ASD. ${ }^{2}$ The parent/guardian being interviewed was asked if they had ever been told by a health professional that their child has an ASD. Parents who responded "yes" were then asked if the child currently has the condition and to describe it as mild, moderate, or severe. Only those children whose parent/guardian responded that they currently had the condition are coded as having an ASD. While the NSCH gathered data on children from the ages of 0 to 17 , only those respondents with

\footnotetext{
${ }^{1}$ The lower response rate for the 2011/2012 wave of the NSCH was primarily due to the inclusion of cell-phone interviews which "provided better coverage of the population of children at the expense of lower response rates" (Blumberg et al. 2013:10). The lower response rates for the cell-phone interviews were due to higher non-resolution rates for those interviews. Also, there is a higher risk of uncorrected coverage bias in the $2007 \mathrm{NSCH}$ due to the lack of use of cell phones when collecting that sample. See Blumberg et al. 2013 for more information on response rates and analysis of nonresponse for the 2011/2012 NSCH.

${ }^{2}$ It is important to note that the NSCH relies on the parent/guardian reporting whether their child has ever been diagnosed with an autism spectrum disorder. It does not verify each child's diagnosis with medical professionals. As will be discussed later, the rates of the disorders found in the 2007 and 2011/2012 waves of the NSCH using parental reporting of diagnoses are found to be reliable compared to studies that utilize clinical validation (Kogan et al. 2009).
} 
a child two years old or older were asked the questions concerning autism. ${ }^{3}$ Across the 2007 and 2011/2012 waves of the NSCH, 2,545 children that were identified as having an ASD (2007:

$921 ; 2011 / 2012: 1624){ }^{4}$

Dependent Variables

Mothers' Mental/Emotional Health. The first measure is mothers' subjective mental/emotional health and it is the sole completely endogenous variable in this analysis (Figure 1). To measure mothers' subjective mental/emotional health both waves of the NSCH asked, "Of children living with mothers in the household (HH), in general, what is the status of mother's mental and emotional health?" Possible responses included "Excellent" = 5, "Very good" = 4, "Good" = 3, "Fair" = 2, and "Poor" = 1. When the respondent was the target child's mother (whether biological, adoptive, foster, or step), she rated her own mental/emotional health. Respondents who were not the child's mother (e.g. father or other relative), gave ratings for the mother's mental/emotional health. The current analysis drops the cases where the mother was not answering about her own mental/emotional health, further reducing the overall sample size to 1,805 children. $^{5}$

\footnotetext{
${ }^{3}$ Concerning ASD specifically, diagnosis at age 2 or later is shown to be reliable, valid, and stable (Lord et al. 2006). Furthermore, research shows parents of children with ASD notice a developmental problem before the child's first birthday, with some differences in communication, social, and fine motor skills evident at 6 months (Bolton et al. 2012; Kozlowski et al. 2011). By limiting the sample to those children aged 2 to 17, the NSCH increases the probability that parents have noticed signs of ASD and sought out professional help.

${ }^{4}$ It is important to note that both waves of the National Survey of Children's Health (NSCH) utilize a complex sampling design. Creating subsamples using listwise deletion for surveys that employ a complex sampling design can be problematic and thus subpopulation analysis is generally encouraged. However, as Bell, Kromrey, and Ferron (2009) show, there is little to no difference in the standard errors generated using listwise deletion and subpopulation techniques on surveys with complex sampling designs. They conclude that it is reasonable to perform analyses on subgroups created using listwise deletion on a survey that utilized a complex sampling design.

${ }^{5}$ Ancillary analyses demonstrate that there are statistically significant differences in the ratings of the mother's mental and emotional health depending on whether the mother answered about herself or a father or other relative answered about the mother. Respondents who were not the mother consistently rated the mother as having a higher mental and emotional health than mothers rated themselves. Results available upon request.
} 
Family Functioning. Family functioning is the second measure used in this analysis. The present analysis uses a standardized and summed index of four questions focused on the stress placed on the family due to the demands of parenting. These questions include: "During the past month, how often have you felt [the sample child] is much harder to care for than most children [his/her] age?", "During the past month, how often have you felt [he/she] does things that really bother you a lot?", “During the past month, how often have you felt angry with [him/her]?”, and "In general, how well do you feel you are coping with the day to day demands of [parenthood/raising children]?" The possible response categories for the first three questions were "Never", "Rarely", "Sometimes", "Usually", "Always” and the final question was "Not very well at all", "Not very well”, "Somewhat well", "Very well”. Each question loaded onto a single factor above 0.56 . The alpha coefficient for the index is 0.68 . The standardization and summing of these questions resulted in a scale that ranges from 4.14 (better overall family functioning) to -15.05 (worse overall family functioning) with a mean and median close to 0 suggesting the distribution is skewed to the left. The questions used in this index are common to scales in other studies of family functioning and childrearing (Fan and Chen 2012). It is important to note that the alpha coefficient for this index is close to but does not exceed the minimally reliable cut-off of 0.70 and results should be interpreted with caution (Nunnally 1978).

Independent Variables

This analysis utilizes three measures of the neighborhoods within which families with a child with an ASD live. The first, "neighborhood support", is an index created from four separate questions: "Do you agree if your child were outside playing and got hurt or scared, there are adults nearby who you trust to help your child?", "Do you agree there are people I can count on 
in this neighborhood?", "Do you agree people in this neighborhood help each other out?", "Do you agree people watch out for each other's children?" Possible responses for each question are either "yes" or "no". Each question loads onto a single factor with all scores above 0.79 . The alpha coefficient for the scale is 0.82 . Higher scores on this scale equate to perceiving a more supportive neighborhood. The second neighborhood measure is a count indicator of the neighborhood amenities available to families. The four questions used to create this count indicator are: "Do sidewalks or walking paths exist in your neighborhood?", "Does a park or a playground exist in your neighborhood?", "Does a recreation center, community center, or boys' or girls' club exist in your community?", and "Does a library or bookmobile exist in your community?" The measure ranges from 0 (no amenities) to 4 (all 4 amenities). The final neighborhood measure is another count indicator of the detractions or deficiencies present in the neighborhood. Three questions are used to create this count indicator: "In your neighborhood, is there litter or garbage on the street or sidewalk?", "In your neighborhood, is there poorly kept or dilapidated housing?", "In your neighborhood is there vandalism such as broken windows or graffiti?" This measure ranges from 0 (no detractions) to 3 (all 3 detractions). These three measures of neighborhood characteristics are robust in prior research (see Fan and Chen 2012).

This analysis utilizes a number of control variables to ensure that the hypothesized relationship between mothers' mental/emotional health, family functioning, and neighborhood conditions is robust. Mother's age (years), child's age (years), the severity of the child's autism diagnosis $($ mild $=0$, moderate $=1$, severe $=2$, child's gender $($ female $=1)$, child's overall health ("Excellent" to "Poor"), child's race (white, Hispanic, black, or other race), family structure (biological parents, step-parents, single mother, other type), child's health insurance coverage (currently insured and for previous 12 months $=1$ ), parents' education level (high school or less, 
some college, college graduate), income (8 categories based on percent of federal income poverty level), child's religious service attendance ("Never" to "Once a week or more"), and size of place (urban $=1$ ) are all included in the analysis.

\section{Method}

First, Table 1 displays descriptive statistics as well as difference of means tests for the dependent variables and independent variables of interest. The analysis uses Mplus 7.3 to estimate simultaneous equation path models which allow for assessments of all of the interrelationships between the exogenous variables and their direct, indirect, and joint effects (Muthén and Muthén 1998-2012). Simultaneous equation path models differ from structural equation modeling (SEM) in that they do not contain measurements of any latent constructs. Essentially, simultaneous equation path modeling is a sub-type of SEM. The models use the WLSMV estimation procedure (weighted least squares, mean and variance adjusted) which is the ideal estimation procedure for categorical dependent variables (Asparouhov and Muthén 2010). WLSMV is a robust weighted least square parameter estimator that uses the diagonal weight matrix in the estimation while the standard errors and the mean and variance adjusted chi-square test statistic utilize a full weight matrix (Muthén and Muthén 1998-2012). Standardized regression coefficients are presented in order to assess substantive importance alongside statistical significance.

A number of different fit statistics are utilized to assess overall model fit. The chi-square test statistic is standard for evaluating model fit, however, it can be sensitive to large sample sizes leading to rejections of model fit even when the model only differs slightly from the underlying structure present in the data. Non-significant chi-squares denote well-fit models that do not differ significantly from the underlying covariance structure in the data. The root mean 
square error of approximation (RMSEA), Tucker-Lewis index (TLI), and comparative fit index (CFI) are also generated and reported. These three fit statistics are affected less by sample sizes and are used in conjunction with the chi-square statistic to assess overall model fit (Jöreskog 1993). An RMSEA value of 0.05 or less, and CFI and TLI values of close to 1 , generally being above 0.90 , indicate good model fit.

\section{Results}

Table 1 reports the descriptive statistics for the subsample of both waves of the NSCH. Table 1 provides statistics for the "No ASD Families", made up only of mothers who responded to the survey who do not have a child with an ASD, alongside the "ASD Families", made up of mothers who were interviewed for the survey who have a child with an ASD as well as the range for each measure. Difference of means tests demonstrate that mothers in the study sample with children with an ASD report significantly lower mental/emotional health than mothers who do not have a child with an ASD $(\mathrm{p}<0.001) .{ }^{6}$ Families of children with an ASD also report significantly worse family functioning $(\mathrm{p}<0.001)$ than those families without a child with an ASD. ${ }^{7}$ Mothers of children with an ASD also report significantly lower levels of neighborhood support $(\mathrm{p}<0.001)$ compared to the neighborhood support perceived by mothers without children with an ASD. ${ }^{8}$ Mothers with and without a child with an ASD report similar levels of neighborhood resources and threats with a significant difference between groups for threats only $(\mathrm{p}<0.001)$.

[Table 1 about here]

\footnotetext{
${ }^{6}$ The score for mental/emotional health for mothers with a child with an ASD is 10 percent lower than mothers who do not have a child with an $\operatorname{ASD}(3.58 / 3.99=0.897 ; 1-0.897=0.103 ; 0.103 \times 100=10.3$ percent $)$.

${ }^{7}$ Families of children with an ASD report a score of -3.02; families without a child with an ASD report a score of 0.04. The mean value for family functioning in the overall sample is 0 and ranges from -15 to 4 . See the Data section for more on this particular measure.

${ }^{8}$ The perceived neighborhood support scores for mothers of children with an ASD are 18 percent lower than for mothers without a child with an ASD $(1.99 / 2.43=0.819 ; 1-.0819=0.181 ; 0.181 \times 100=18.1$ percent $)$.
} 
Figure 1 reports the results from the simultaneous equation path models. The model fit statistics suggest that the model-implied covariance matrix does not differ significantly from the observed matrix. First, the chi-square statistic is non-significant $(p=0.393)$. The other fit statistics are also either at or very near their ideal values. The RMSEA is less than 0.05. The CFI (0.999) and TLI (0.996) are either at or extremely close to their ideal value of 1 . Taken together, the fit statistics suggest a good overall model fit (Jöreskog 1993).

Results from the simultaneous equation path models show that neighborhood conditions are significantly associated with the mental/emotional health of mothers' of children with an ASD and overall family functioning. First, family functioning $(\beta=0.36 ; p<0.001)$ is strongly and positively associated with the mental/emotional health of mothers' of children with an ASD. Among the neighborhood conditions measures, neighborhood support is significantly associated with family functioning $(\beta=0.10 ; \mathrm{p}<0.001)$ and mothers' mental/emotional health $(\beta=0.14$; $\mathrm{p}<0.001) .{ }^{9}$ Neighborhood support has the third strongest standardized effect on both family functioning and mothers' mental/emotional health. Neither neighborhood resources nor neighborhood threats are significantly associated with the family functioning or mothers' mental/emotional health for families with a child with an ASD. ${ }^{10}$ Concerning the control variables, increasing age for mothers' of children with an ASD is significantly and negatively associated with both family functioning $(\beta=-0.06 ; \mathrm{p}<0.01)$ and mothers' mental/emotional health $(\beta=-0.09 ; \mathrm{p}<0.05)$. However, increasing age for the child is significantly and positively

\footnotetext{
${ }^{9}$ Zhao, Lynch, and Chen (2010) provide a corrective to Baron and Kenny's (1989) much-cited procedure for establishing mediation. In their decision tree for establishing and understanding types of mediation and nonmediation, complementary mediation exists when a significant indirect effect $(X \rightarrow M \rightarrow Y)$ and a significant direct effect $(X \rightarrow Y)$ are both present and are of the same sign. Zhao and colleagues argue that the persistence of a direct effect signals the possibility of an omitted mediator which serves to further the advancement of the theoretical framework. I return to this in the discussion section below.

${ }^{10}$ Following Zhao et al. (2010), the relationship between neighborhood threats and neighborhood resources, family functioning, and mothers' mental and emotional health can be classified as no-effect non mediation. The implications of this finding are discussed further in the discussion section below.
} 
associated with family functioning $(\beta=0.08 ; \mathrm{p}<0.05)$ but not mothers' mental/emotional health. Child's overall health is strongly and positively associated with both family functioning ( $\beta=$ $0.20 ; \mathrm{p}<0.001)$ and mothers' mental/emotional health $(\beta=0.15 ; \mathrm{p}<0.001)$. Higher income $(\beta=$ $0.10 ; \mathrm{p}<0.001)$ and more frequent religious service attendance for the child $(\beta=0.06 ; \mathrm{p}<0.001)$ are both positively associated with mothers' mental/emotional health. The reported severity of the child's autism is not significantly associated with mother's mental/emotional health, but is negatively and significantly associated with family functioning $(\beta=-0.13 ; \mathrm{p}<0.001)$. Other family type is positively associated with family functioning $(\beta=0.08 ; \mathrm{p}<0.05)$ as is being black compared to white $(\beta=0.06 ; \mathrm{p}<0.05)$. The child's gender, health insurance coverage, parental education, size of place, and race/ethnicity are all non-significant in the path model.

[Figure 1 about here]

Table 3 displays the direct, indirect, and total standardized effects of the significant predictors of the mental/emotional health of mothers of children with an ASD. The relationship between overall family functioning, neighborhood support, and mothers' mental/emotional health can be classified as complementary mediation (Zhao, Lynch, and Chen 2010).

Neighborhood support has the third highest total standardized effect in the model $(\beta=0.18)$ with an indirect effect through family functioning on mothers' mental/emotional health of $\beta=0.036$. Family functioning has the highest total effect on the mental/emotional health of mothers of children with an ASD with a total standardized effect of $\beta=0.36$. Child's overall health has the second highest total standardized effect. Income, mother's age, child's frequency of religious service attendance, child's age, severity of the autism diagnosis, and other family type follow.

[Table 2 about here]

\section{Discussion}


Results from the simultaneous equation path models confirm that (1) only some neighborhood conditions, specifically perceived neighborhood support, are significantly associated with the subjective mental and emotional health of mothers' of children with an ASD and overall family functioning, and (2) that the relationship between overall family functioning, neighborhood support, and mothers' mental and emotional health is one of complementary mediation, where both direct and indirect effects are present (Zhao et al. 2010). Mothers of children with an ASD who perceive support from those in their neighborhood report stronger mental and emotional health as well as improved family functioning, which is strongly associated with improved mental and emotional health. Perceiving that people in the neighborhood can be counted on, help each other out, watch out for each other's children, and that there are adults nearby who can be trusted to help a hurt or scared child is vital to the mental and emotional health of mothers of children with an ASD and the overall functioning of these families. The collective efficacy of a neighborhood has a positive influence on both family functioning and physical and mental health outcomes in the broader population as well as those families with children with disabilities, broadly defined (Chu et al. 2004; Fan and Chen 2012; Mannon and Brooks 2006; Park et al. 2002).

The present study extends this work to look specifically at families with children with an ASD and finds a consistent effect; social support from the neighborhood plays a vital role in the subjective quality of life of a family by improving family functioning and mental and emotional health of the mother in families with children with an ASD. These findings provide strong evidence for the importance of a particular type of informal support (Boyd 2002). However, mothers of children with an ASD report significantly lower levels of neighborhood support compared to mothers who do not have a child with an ASD (see Table 1). This suggests that 
families most in need of this form of support are least likely to perceive it. It is important for future research on families of children with an ASD to account for neighborhood social support and collective efficacy - the context portion of the process-person-context model - when investigating subjective quality of life. Furthermore, the continued presence of a significant direct effect between neighborhood support and mothers' mental and emotional health indicates the possibility of an omitted mediator (Zhao et al. 2010). It could be that other aspects of family life beyond family functioning mediate the relationship between neighborhood support and mothers' mental health. As Zhao and coauthors (2010) point out, finding complementary mediation should serve as an impetus for future research to continue to examine this relationship and identify other possible mediators of a particular direct effect.

Conversely, neighborhood detractions like litter or garbage, rundown housing, or signs of vandalism (graffiti, broken windows) are not significantly associated with the mental and emotional health of mothers with children with an ASD or their family's overall functioning. This is counter to previous work that finds that deficiencies in the neighborhood environment negatively affects mental health and family functioning in the broader population (Ellen et al. 2001; Guite et al. 2006). Similarly, neighborhood amenities like walking paths, parks, community centers, and libraries are not significantly associated with either family functioning or mother's mental emotional health within families of children with an ASD. This finding is particularly surprising given the importance of community amenities concerning family functioning and mental health in prior literature focused on the general population (Chu et al. 2004; Fan and Chen 2012; Guite et al. 2006). It could be that tendencies toward social isolation for families with a child with an ASD results in fewer opportunities to interact with their community's physical environment (Gray 2002). Future research could explore the level to 
which families of children with an ASD experience their physical surroundings and the influence those surroundings have on both family functioning and mental and emotional health.

The findings also emphasize the importance of viewing the families of special needs children, the individuals who compose those families, and their surrounding environment as codependent and integral systems. As the ecological model stipulates, human outcomes are influenced by a series of embedded social systems (Bronfenbrenner 1977, 1986, 1994, 1999). In the present study, the proximal processes of interpersonal interaction within the family and interaction with the surrounding environmental context appear to play a significant role in determining mothers' mental health, supporting the process-person-context model (Bronfenbrenner 1994, 1999). Neighborhood social support (context) has both a direct and indirect ameliorating influence on mothers' mental health (person). The indirect influence of neighborhood social support is through family functioning (process), which has a strong and positive effect on mothers' mental health. Future research investigating quality of life, behavioral, or health outcomes for individuals in families of children with autism should continue to consider the broader ecological context within which each family is found.

The results also highlight that improved family functioning is integral to better mental and emotional health for mothers, particularly those with a child with an ASD. This finding is in line with prior literature that shows the increased parental responsibility of mothers of children with and ASD adversely affects them in myriad ways (Hastings 2008; Hayes and Watson 2013; Jones et al. 2013; Sawyer et al. 2010). Compared to the general population, families with children with an ASD report significantly worse family functioning (Table 1; also Sikora et al. 2013). It will also be important for future research to examine the relationship between neighborhood support, family functioning, and mothers' mental and emotional health for 
families with children who are developing normally or who suffer from other types of disabilities like ADHD, Down's syndrome, or a learning disorder. While beyond the purview of the present analysis, it may be that these relationships differ somewhat depending on the type of disability in question, or the lack thereof.

Beyond mothers' mental and emotional health, family functioning, and neighborhood conditions, the overall health of the child with an ASD is integral to family quality of life as is the severity of their autism diagnosis. Even among children with ASD, families with children who have lower levels of overall health report lower family functioning and lower mental and emotional health for the mother. Likewise, as the severity of a child's autism increases from mild to moderate to severe, family functioning decreases. While autism severity does not directly affect mother's mental and emotional health in this model, it indirectly influences it through its direct effect on family functioning. This finding highlights the importance of accounting for the severity of a child's autism given ASD are complex disorders that rarely present in identical forms. Incorporating complexity in quantitative studies of ASD regarding severity is important. Mother's age is the only other control variable that evinces both a direct and indirect effect on mental and emotional health. It appears that older mothers of children with an ASD experience worse family functioning and lower subjective mental and emotional health than younger mothers. The association between age and mental health is complex (see Blanchflower and Oswald 2008), but it may be that the additional challenges of caring for a child with an ASD are particularly difficult for older mothers. Finally, the child's frequency of attendance at religious services is directly and positively associated with mothers' mental and emotional health. Contrary to previous research (Coulthard and Fitzgerald 1999; Ekas et al. 2009; Tarakeshwar and 
Pargament 2001), this finding highlights a possible positive influence of religious activity on the mental health of mothers of children with an ASD (Gray 2001).

While this analysis presents the first examination of the relationship between neighborhood conditions, family functioning, and mothers' mental and emotional health in families with children with an ASD, several limitations deserve mention. First, the NSCH relies on parental reports regarding each child's diagnosis. These are not verified by medical professionals. However, the NSCH is used in prior research on ASD (Zablotsky et al. 2013) and the rates of the disorders found in each wave of the NSCH are found to be reliable compared to studies that utilize clinical validation (Kogan et al. 2009). Second, there are limitations to using one item to measure mothers' overall mental and emotional health despite evidence that the straightforwardness of single item measures can be advantageous (Bowling 2005). While much research on families with children with an ASD employ large batteries of questions on mothers' emotional and mental health, all of them utilize rather small convenience samples that significantly limit their external validity. For example, one meta-analysis on the experience of parenting stress in parents of children with an ASD found the largest sample size in the literature was 265 , the majority of studies used sample sizes between 30 and 50, with a mean sample size of 50 (Hayes and Watson 2013). The current study significantly improves upon this limitation concerning generalizability and is in line with prior research (Zablotsky et al. 2013).

Furthermore, this study uses only the self-reports of mothers' mental/emotional health. It could be that a mothers' actual mental/emotional health significantly influences her reported mental/emotional health. Also, the development of the NSCH was led by the Maternal and Child Health Bureau in collaboration with a national technical expert panel and the National Center for 
Health Statistics (NCHS). The survey items were assessed during a pretest phase with revisions being made as needed (see Blumberg et al. 2012).

Third, the data used in this study is cross-sectional. This precludes any attempt at making concrete causal inferences. While the pathways pictured in Figure 1 fit the underlying covariance matrix of the observed data set, additional causal paths could exist. For instance, mothers' mental/emotional health could be hypothesized to influence family functioning. Future studies using large, representative, longitudinal data on families of children with an ASD are needed to continue to explicate the complex relationships between mental health, family functioning, and social context. Fourth, the alpha coefficient for the family functioning index is close to but does not exceed the minimally reliable cut-off of 0.70 (Nunnally 1978). Future research would do well to include additional items of family functioning in order to provide a more exhaustive representation of family life. While beyond the purview of the current study, recent research also shows that parental estimates of family functioning may influence their rating of severity for their child's autism (Zablotsky, Bramlett, and Blumberg 2015). Future studies could incorporate this additional wrinkle into the path analysis. Finally, the NSCH lacks any direct measures of the levels of support mothers receive from their extended families and/or friends. Prior research highlights the importance of these networks (Boyd 2002; Sikora et al. 2013).

\section{Conclusion}

Using a large, nationally-representative data set and employing a process-person-context model this analysis provides evidence of the importance of neighborhood support for family life by showing improved family functioning and mothers' subjective mental and emotional health for families with children with an ASD. A sense of collective efficacy with neighbors not only encourages mental and emotional wellbeing for mothers of children with an ASD, it also 
encourages improved family functioning which positively influences mothers' mental and emotional health. Unlike in the general population, the physical surroundings of the neighborhood, whether amenities or deficiencies, are not significantly associated with either improved family functioning or the mental and emotional health of mothers with children with an ASD. A future qualitative study that builds off of these preliminary findings is a necessity to provide a more thorough explanation of the underlying mechanisms of the relationships presented here. While large-scale survey data provides particular advantages, future qualitative work will provide a deeper understanding of the challenges that mothers of children with autism face and the importance of neighborhood context.

Given the rapid increase of autism diagnoses where 1 in 68 children are now diagnosed with an ASD (CDC 2014), the implications of these findings are significant. Healthcare workers, social workers, educators, and community organizers must examine parents and families in context and recognize the neighborhood as a vital part of the overall support network for families with a child with an ASD. Connecting these families to the people in their community in order to lessen their social isolation is integral to improving overall well-being and quality of life. These findings should also encourage families of children with an ASD to recognize the importance of connecting themselves to their neighbors. However, in situations where neighborhood social support is structurally unavailable, other forms of social support must be made available to these families. The increased levels of stress associated with raising a child with an ASD cannot be borne by the family alone; it takes a large and supportive cast of which neighbors are an important part (Bronfenbrenner 1977, 1994, 1999). 


\section{References}

Asparouhov, T., \& Muthén, B. (2010). Weighted least squares estimation with missing data. MplusTechnical Appendix.

Baron, R. M. and D. A. Kenny. (1986). The moderator-mediator variable distinction in social psychological research: Conceptual, strategic, and statistical considerations. Journal of Personality and Social Psychology, 51(6), 1173-1182.

Bayat, M. (2007). Evidence of resilience in families of children with autism. Journal of Intellectual Disability Research, 51, 9, 702-714.

Bell, Bethany A., Jeffrey D. Kromrey, and John M. Ferron. (2009). Missing data and complex samples: The impact of listwise deletion vs. subpopulation analysis on statistical bias and hypothesis test results when data are MCAR and MAR. In Proceedings of the Joint Statistical Meetings, Survey Research Methods Section, 2009.

Benjak, T., Vuletić, G., \& Kolarić, B. (2011). Subjective quality of life for parents of children with autism spectrum disorders in Croatia. Applied Research in Quality of Life, 6, 91-102.

Bishop, S. L., Richler, J., Cain, A. C., Lord, C., \& Floyd, F. (2007). Predictors of perceived negative impact in mothers of children with autism spectrum disorder. American Journal on Mental Retardation, 112, 6, 450-461.

Blanchflower, D. G., \& Oswald, A. J. (2008). Is well-being U-shaped over the life cycle? Social Science \& Medicine, 66, 8, 1733-1749.

Blumberg, S. J., Bramlett, M. D., Kogan, M. D., Schieve, L. A., Jones, J. R., \& Lu, M. C. (2013). Changes in prevalence of parent-reported autism spectrum disorder in school-aged US children: 2007 to 2011-2012. National Health Statistics Reports, 65, 20, 1-7.

Blumberg, S. J., Foster, E. B., Frasier, A. M., Satorius, J., Skalland, B. J., Nysse-Carris, K. L. et al. (2012). Design and operation of the national survey of children's health. 2007 Vital and Health Statistics.Ser.1, Programs and Collection Procedures, 55, 1-149. 
Bolton, P. F., Golding, J., Emond, A., \& Steer, C. D. (2012). Autism spectrum disorder and autistic traits in the Avon longitudinal study of parents and children: Precursors and early signs. Journal of the American Academy of Child \& Adolescent Psychiatry, 51, 249-260. e25.

Bowling, A. (2005). Just one question: If one question works, why ask several? Journal of Epidemiology and Community Health, 59, 5, 342-345.

Boyd, B. A. (2002). Examining the relationship between stress and lack of social support in mothers of children with autism. Focus on Autism and Other Developmental Disabilities, 17, 4, 208-215.

Bromley, J., Hare, D. J., Davison, K., \& Emerson, E. (2004). Mothers supporting children with autistic spectrum disorders: Social support, mental health status and satisfaction with services. Autism: The International Journal of Research and Practice, 8, 4, 409-423.

Bronfenbrenner, U. (1977). Toward an experimental ecology of human development. American Psychologist, 32, 515-531.

Bronfenbrenner, U. (1986). Ecology of the family as a context for human development: Research Perspectives. Developmental Psychology, 22(6), 723-742.

Bronfenbrenner, U. (1994). Ecological models of human development. In T. Husten \& T.N. Postlethewaite (Eds.), International Encyclopedia of Education (2 ${ }^{\text {nd }}$ Ed., Vol. 3) pp. 1643-1657, NY: Freeman.

Bronfenbrenner, U. 1999. Environments in developmental perspective: Theoretical and operational models. In S.L. Friedman \& T.D. Wachs (Eds.), Measuring environment across the life span: Emerging methods and concepts (pp. 3-28). Washington, DC: American Psychological Press.

Cattell, V. (2001). Poor people, poor places, and poor health: The mediating role of social networks and social capital. Social Science \& Medicine, 52, 10, 1501-1516.

Chiri, G., \& Warfield, M. E. (2012). Unmet need and problems accessing core health care services for children with autism spectrum disorder. Maternal and Child Health Journal, 16, 5, 1081-1091.

Chu, A., Thorne, A., \& Guite, H. (2004). The impact on mental well-being of the urban and physical environment: An assessment of the evidence. Journal of Public Mental Health, 3, 2, 17-32. 
Coulthard, P., \& Fitzgerald, M. (1999). In god we trust? Organized religion and personal beliefs as resources and coping strategies, and their implications for health in parents with a child on the autistic spectrum. Mental Health, Religion \& Culture, 2, 1, 19.

Dabrowska, A., \& Pisula, E. (2010). Parenting stress and coping styles in mothers and fathers of preschool children with autism and Down syndrome. Journal of Intellectual Disability Research, 54, 266-280.

Centers for Disease Control and Prevention (CDC). (2014). Prevalence of autism spectrum disorder among children aged 8 years - autism and developmental disabilities monitoring network, 11 sites, United States, 2010. Morbidity and Mortality Weekly Report. Surveillance Summaries (Washington, D.C.: 2002), 63, 2, 1-21.

Ekas, N. V., Lickenbrock, D. M., \& Whitman, T. L. (2010). Optimism, social support, and well-being in mothers of children with autism spectrum disorder. Journal of Autism and Developmental Disorders, 40(10), 1274-1284.

Ekas, N. V., Whitman, T. L., \& Shivers, C. (2009). Religiosity, spirituality, and socioemotional functioning in mothers of children with autism spectrum disorder. Journal of Autism and Developmental Disorders, 39, 5, 706-719.

Ellen, I. G., Mijanovich, T., \& Dillman, K. (2001). Neighborhood effects on health: Exploring the links and assessing the evidence. Journal of Urban Affairs, 23, 3-4, 391-408.

Farrugia, D. (2009). Exploring stigma: Medical knowledge and the stigmatisation of parents of children diagnosed with autism spectrum disorder. Sociology of Health \& Illness 31, 7, 1011-1027.

Fan, Y., \& Chen, Q. (2012). Family functioning as a mediator between neighborhood conditions and children's health: Evidence from a national survey in the United States. Social Science \& Medicine, 74, 12, 1939-1947.

Francis, A. (2012). The dynamics of family trouble: Middle-class parents whose children have problems. Journal of Contemporary Ethnography, 41, 4, 371-401. 
Gale, C. R., Dennison, E. M., Cooper, C., \& Sayer, A. A. (2011). Neighbourhood environment and positive mental health in older people: The Hertfordshire cohort study. Health \& Place, 17, 4, 867-874.

Gonzalez, M. C., Hidalgo, C. A., \& Barabasi, A. (2008). Understanding individual human mobility patterns. Nature, 453, 7196, 779-782.

Gray, D. E. (1997). High functioning autistic children and the construction of "normal family life". Social Science \& Medicine 44, 8, 1097-1106.

Gray, D. E. (2001). Accommodation, resistance and transcendence: Three narratives of autism. Social Science \& Medicine, 53, 9, 1247-1257.

Gray, D. E. (2002). 'Everybody just freezes. Everybody is just embarrassed': Felt and enacted stigma among parents of children with high functioning autism. Sociology of Health \& Illness, 24, 6 , 734-749.

Gray, D. E. (2003). Gender and coping: The parents of children with high functioning autism. Social Science \& Medicine, 56, 3, 631-642.

Gray, D. E. (2006). Coping over time: The parents of children with autism. Journal of Intellectual Disability Research, 50, 12, 970-976.

Guite, H., Clark, C., \& Ackrill, G. (2006). The impact of the physical and urban environment on mental well-being. Public Health, 120, 12, 1117-1126.

Hastings, R. P. (2003). Child behaviour problems and partner mental health as correlates of stress in mothers and fathers of children with autism. Journal of Intellectual Disability Research, 47, 4-5, 231-237.

Hastings, R. P. (2008). Stress in parents of children with autism. In E. McGregor, M. Nunez, D. Cebula \& J. C. Gomez (Eds.), Autism: An integrated view from neuroscience, clinical, and intervention research. (pp. 303-324). London: Blackwell. 
Hastings, R. P., Kovshoff, H., Brown, T., Ward, N. J., Espinosa, F. D., \& Remington, B. (2005). Coping strategies in mothers and fathers of preschool and school-age children with autism. Autism: The International Journal of Research and Practice, 9, 4, 377-391.

Hayes, S. A., \& Watson, S. L. (2013). The impact of parenting stress: A meta-analysis of studies comparing the experience of parenting stress in parents of children with and without autism spectrum disorder. Journal of Autism and Developmental Disorders, 43, 3, 629-642.

Jones, R., Heim, D., Hunter, S., \& Ellaway, A. (2014). The relative influence of neighbourhood incivilities, cognitive social capital, club membership and individual characteristics on positive mental health. Health \& Place, 28, 187-193.

Jones, L., Totsika, V., Hastings, R. P., \& Petalas, M. A. (2013). Gender differences when parenting children with autism spectrum disorders: A multilevel modeling approach. Journal of Autism and Developmental Disorders, 43, 9, 2090-2098.

Khanna, R., Madhavan, S. S., Smith, M. J., Patrick, J. H., Tworek, C., \& Becker-Cottrill, B. (2011). Assessment of health-related quality of life among primary caregivers of children with autism spectrum disorders. Journal of Autism and Developmental Disorders, 41, 9, 1214-1227.

Kogan, M. D., Blumberg, S. J., Schieve, L. A., Boyle, C. A., Perrin, J. M., Ghandour, R. M., et al. (2009). Prevalence of parent-reported diagnosis of autism spectrum disorder among children in the US, 2007. Pediatrics, 124, 5, 1395-1403.

Kogan, M. D., Strickland, B. B., Blumberg, S. J., Singh, G. K., Perrin, J. M., \& van Dyck, P. C. (2008). A national profile of the health care experiences and family impact of autism spectrum disorder among children in the United States, 2005-2006. Pediatrics, 122, 6, e1149-58.

Kozlowski, A. M., Matson, J. L., Horovitz, M., Worley, J. A., \& Neal, D. (2011). Parents' first concerns of their child's development in toddlers with autism spectrum disorders. Developmental Neurorehabilitation, 14(2), 72-78.

Lai, W. W., \& Oei, T. P. S. (2014). Coping in parents and caregivers of children with autism spectrum disorders (ASD): A review. Review Journal of Autism and Developmental Disorders, 207-224. 
Liu, K. Y., King, M., \& Bearman, P. S. (2010). Social influence and the autism epidemic. American Journal of Sociology, 115, 5, 1387-1434.

Lord, C., Risi, S., DiLavore, P. S., Shulman, C., Thurm, A., \& Pickles, A. (2006). Autism from 2 to 9 years of age. Archives of General Psychiatry, 63(6), 694-701.

Mannon, S. E., \& Brooks, W. T. (2006). Neighborhood family-friendliness and its effect on family relations: Evidence from Utah. Sociological Spectrum, 26, 4, 405-421.

Miller, J. E., Nugent, C. N., \& Russell, L. B. (2015). Risk factors for family time burdens arranging and providing health care for children with special health care needs: Lessons from nonproportional odds models. Social Science Research DOI: http://dx.doi.org/10.1016/j.ssresearch.2015.04.003.

Muthen, L. K., \& Muthen, B. O. (2012). Mplus: Statistical analysis with latent variables: User's guide. Los Angeles, CA: Muthen \& Muthen.

Nunnally, J. C. (1978). Psychometric Theory, $2^{\text {nd }}$ edition. New York, NY: McGraw-Hill.

Park, J., Turnbull, A. P., \& Turnbull, H. R. (2002). Impacts of poverty on quality of life in families of children with disabilities. Exceptional Children, 68, 2, 151-170.

Parner, E. T., Schendel, D. E., \& Thorsen, P. (2008). Autism prevalence trends over time in Denmark: Changes in prevalence and age at diagnosis. Archives of Pediatrics \& Adolescent Medicine, 162, 12, $1150-1156$.

Sawyer, M. G., Bittman, M., La Greca, A. M., Crettenden, A. D., Harchak, T. F., \& Martin, J. (2010). Time demands of caring for children with autism: What are the implications for maternal mental health? Journal of Autism and Developmental Disorders, 40, 5, 620-628.

Sayer, Linda C. (2005). Gender, time and inequality: Trends in women's and men's paid work, unpaid work and free time. Social Forces 84(1), 285-303.

Schieve, L. A., Rice, C., Yeargin-Allsopp, M., Boyle, C. A., Kogan, M. D., Drews, C., \& Devine, O. (2012). Parent-reported prevalence of autism spectrum disorders in US-born children: An assessment of changes within birth cohorts from the 2003 to the 2007 national survey of Children's health. Maternal and Child Health Journal, 16, 1, 151-157. 
Sikora, D., Moran, E., Orlich, F., Hall, T. A., Kovacs, E. A., Delahaye, J., et al. (2013). The relationship between family functioning and behavior problems in children with autism spectrum disorders. Research in Autism Spectrum Disorders, 7, 2, 307-315.

South, S. J. (2001). The geographic context of divorce: Do neighborhoods matter? Journal of Marriage and Family, 63, 3, 755-766.

South, S. J., \& Crowder, K. D. (1999). Neighborhood effects on family formation: Concentrated poverty and beyond. American Sociological Review, 64, 1, 113-132.

South, S. J., \& Lloyd, K. M. (1995). Spousal alternatives and marital dissolution. American Sociological Review, 60, 1, 21-35.

Tarakeshwar, N., \& Pargament, K. I. (2001). Religious coping in families of children with autism. Focus on Autism and Other Developmental Disabilities, 16, 4, 247-260.

Trent, K., \& South, S. J. (2003). Spousal alternatives and marital relations. Journal of Family Issues, 24, 6, 787-810.

Truong, K. D., \& Ma, S. (2006). A systematic review of relations between neighborhoods and mental health. The Journal of Mental Health Policy and Economics, 9, 3, 137-154.

Zablotsky, B., Bradshaw, C. P., \& Stuart, E. A. (2013). The association between mental health, stress, and coping supports in mothers of children with autism spectrum disorders. Journal of Autism and Developmental Disorders 43, 6, 1380-1393.

Zhao, Xinshu, John G. Lynch Jr., and Qimei Chen. (2010). Reconsidering Baron and Kenny: Myths and Truths about Mediation Analysis. Journal of Consumer Research, 37, 197206. 
Table 1: Descriptive Statistics of Study Sample (Mothers of ASD Children) and Full Sample (Mothers Only)

\begin{tabular}{|c|c|c|c|c|c|}
\hline & \multicolumn{2}{|c|}{ ASD Families } & \multicolumn{3}{|c|}{ No ASD Families } \\
\hline & $\begin{array}{c}\text { Mean or } \\
\%\end{array}$ & SD & Range & Mean or \% & SD \\
\hline \multicolumn{6}{|l|}{ Endogenous Variables } \\
\hline $\begin{array}{l}\text { Mothers' Mental/Emotional } \\
\text { Health }\end{array}$ & $3.58 *$ & 1.00 & $1-5$ & 3.99 & 0.90 \\
\hline Family Functioning & $-3.02 *$ & 3.44 & $-15-4$ & -0.04 & 2.83 \\
\hline \multicolumn{6}{|l|}{ Neighborhood Conditions } \\
\hline Neighborhood Support & $1.99 *$ & 1.60 & $0-4$ & 2.43 & 1.56 \\
\hline Neighborhood Resources & 3.07 & 1.16 & $0-4$ & 3.08 & 1.14 \\
\hline Neighborhood Threats & $0.48 *$ & 0.85 & $0-4$ & 0.41 & 0.76 \\
\hline \multicolumn{6}{|l|}{ Control Variables } \\
\hline Mother's Age & 41.49 & 7.98 & $20-59$ & 40.03 & 7.94 \\
\hline Child's Age & 10.40 & 4.09 & $2-17$ & 9.99 & 4.69 \\
\hline Female Child & 19.24 & --- & --- & 48.91 & --- \\
\hline Child's Overall Health & 3.82 & 1.08 & $1-5$ & 4.49 & 0.79 \\
\hline Severity of Autism: Mild & 55.77 & --- & --- & --- & --- \\
\hline $\begin{array}{l}\text { Severity of Autism: } \\
\text { Moderate }\end{array}$ & 33.65 & --- & --- & --- & --- \\
\hline Severity of Autism: Severe & 10.58 & --- & --- & --- & --- \\
\hline $\begin{array}{l}\text { Child's Health Insurance } \\
\text { Coverage }\end{array}$ & 91.29 & --- & --- & 89.43 & --- \\
\hline Parent's Education & 2.57 & 0.65 & $1-3$ & 2.50 & 0.69 \\
\hline Income & 5.36 & 2.60 & $1-8$ & 5.70 & 2.54 \\
\hline $\begin{array}{l}\text { Child Religious Service } \\
\text { Attendance }\end{array}$ & 1.61 & 1.30 & $0-3$ & 2.01 & 1.19 \\
\hline Urban & 75.68 & --- & --- & 73.15 & --- \\
\hline White $\dagger$ & 72.78 & --- & --- & 68.39 & --- \\
\hline Hispanic & 9.41 & --- & --- & 13.19 & --- \\
\hline Black & 7.09 & --- & --- & 9.58 & --- \\
\hline Multiple Races & 10.52 & --- & --- & 8.99 & --- \\
\hline Biological Parents $\dagger$ & 63.04 & --- & --- & 70.53 & --- \\
\hline Step-Parents & 7.94 & --- & --- & 8.23 & --- \\
\hline Single Mother & 27.97 & --- & --- & 20.41 & --- \\
\hline Other Family Type & 0.55 & --- & --- & 0.51 & --- \\
\hline
\end{tabular}

Source: NSCH 2007 \& 2011/2012

$*_{p}<0.001$; Significant difference between families with ASD child and families without ASD child via t-test analysis

$\dagger$ Reference categories 
Table 2: Direct, Indirect, and Total Standardized Effects for Significant Variables Predicting Mothers' Mental/Emotional Health and Family Functioning for Families with Children with an ASD

\begin{tabular}{|c|c|c|c|c|}
\hline & \multirow[b]{2}{*}{$\begin{array}{l}\text { Direct } \\
\text { Association with } \\
\text { Mothers' } \\
\text { Mental/Emotional } \\
\text { Health }\end{array}$} & \multicolumn{2}{|c|}{ Indirect Association Calculation } & \multirow[b]{2}{*}{$\begin{array}{l}\text { Total Association } \\
\text { with Mothers' } \\
\text { Mental/Emotional } \\
\text { Health }\end{array}$} \\
\hline & & $\begin{array}{l}\text { Direct } \\
\text { Association } \\
\text { with Family } \\
\text { Functioning }\end{array}$ & $\begin{array}{l}\text { Indirect } \\
\text { Association with } \\
\text { Mothers' } \\
\text { Mental/Emotional } \\
\text { Health }\end{array}$ & \\
\hline $\begin{array}{l}\text { Family } \\
\text { Functioning }\end{array}$ & 0.36 & --- & --- & 0.36 \\
\hline $\begin{array}{l}\text { Neighborhood } \\
\text { Support }\end{array}$ & 0.14 & 0.10 & 0.036 & 0.18 \\
\hline Mother's Age & -0.09 & -0.06 & -0.022 & -0.11 \\
\hline Child's Age & --- & 0.08 & 0.029 & 0.03 \\
\hline $\begin{array}{l}\text { Child's Overall } \\
\text { Health }\end{array}$ & 0.15 & 0.20 & 0.072 & 0.22 \\
\hline $\begin{array}{l}\text { Severity of } \\
\text { Autism }\end{array}$ & --- & -0.13 & -0.047 & -0.05 \\
\hline $\begin{array}{l}\text { Income } \\
\text { Child Religious }\end{array}$ & 0.10 & --- & --- & 0.10 \\
\hline $\begin{array}{l}\text { Service } \\
\text { Attendance }\end{array}$ & 0.06 & --- & --- & 0.06 \\
\hline $\begin{array}{l}\text { Other Family } \\
\text { Type }\end{array}$ & --- & 0.08 & 0.029 & 0.03 \\
\hline
\end{tabular}

Note: Only pathways from Figure 1 that were significant are included. 
Figure 1: Path Model for Process-Person-Context Model of Mental Health for Mothers' with Child with Autism

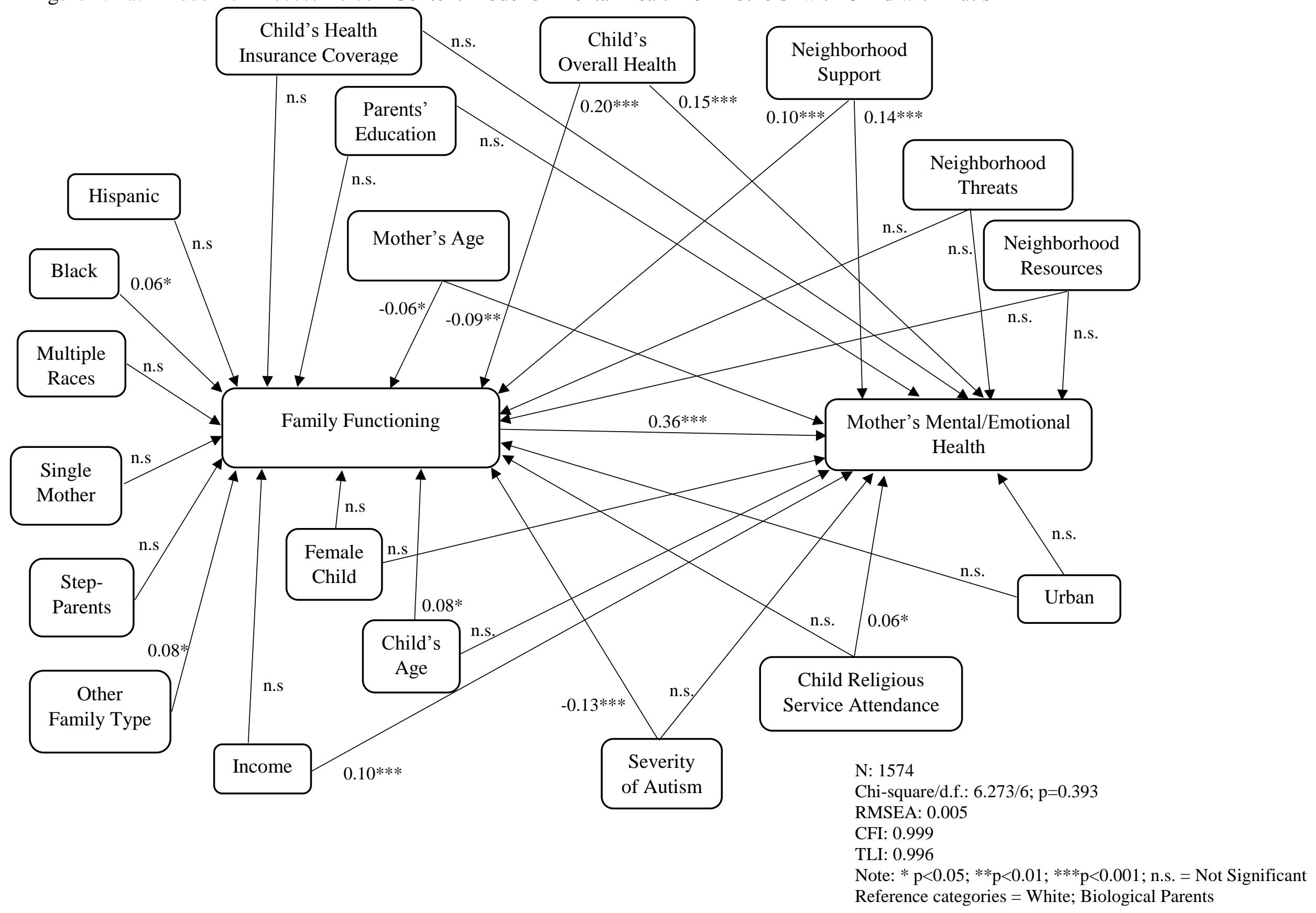

